\title{
Employee and Customer Reactions to a Healthy In-Store Marketing Intervention in Supermarkets
}

\author{
Erica L. Davis ${ }^{1}$, Alexis C. Wojtanowski ${ }^{2}$, Stephanie Weiss ${ }^{3}$, Gary D. Foster ${ }^{2}$, Allison Karpyn ${ }^{3} \&$ Karen Glanz $^{4}$ \\ ${ }^{1}$ Perelman School of Medicine, University of Pennsylvania, Philadelphia, PA, USA \\ ${ }^{2}$ Center for Obesity Research and Education, Temple University, Philadelphia, PA, USA \\ ${ }^{3}$ The Food Trust, Philadelphia, PA, USA \\ ${ }^{4}$ Perelman School of Medicine and School of Nursing, University of Pennsylvania, Philadelphia, PA, USA \\ Correspondence: Erica L. Davis, Center for Health Behavior Research, The University of Pennsylvania, 813 \\ Blockley Hall, 423 Guardian Dr, Philadelphia, PA 19104, USA. Tel: 1-215-898-8797. Fax: 1-215-573-5315. \\ E-mail: edavi@upenn.edu
}

Received: October 7, 2015 Accepted: November 10, 2015 Online Published: January 19, 2016

doi:10.5539/jfr.v5n1p107 URL: http://dx.doi.org/10.5539/jfr.v5n1p107

\begin{abstract}
Supermarkets are a primary source of food for American households, and increased presence in low-income, high-minority neighborhoods present opportunities to increase access to healthy foods. It is important to assess store manager and customer reactions to in-store marketing interventions. The objective was to evaluate manager and customer reactions to stealth, low-cost, sustainable in-store marketing strategies to promote healthier purchases in five product categories and gain insight into shopping habits and willingness to change behaviors. Surveys were collected as part of the evaluation of a cluster-randomized controlled trial conducted from 2011-2012 in eight urban supermarkets in low-income, high-minority neighborhoods. Store manager $(n=16)$ and customer intercept surveys $(\mathrm{n}=100)$ were administered at intervention stores in May-July 2012 and August 2012, respectively. Demographics, shopping habits, and impact were calculated using frequency distributions, cross-tabulation, and analyses of variance. Correlations were calculated using Pearson's R or one-sided Fisher's Exact Test. Most managers reported the project had a positive impact on stocking, ordering, staffing, and interaction with other employees. Most customers did not notice new marketing strategies, although they were intentionally stealth. A large number of customers reported making impulse purchases regularly. Opportunities to positively affect purchasing may exist.
\end{abstract}

Keywords: in-store marketing, healthy food shopping, grocery stores, evaluation, supermarket

\section{Introduction}

Supermarkets are one of the primary sources of food for American households, with $85 \%$ of shoppers regularly using traditional supermarkets. (FMI, 2014) On average, shoppers made 1.5 grocery trips per week, spending $\$ 100.80$. (FMI, 2015) Traditional supermarkets can provide opportunities to increase access to healthier foods, potentially improving health outcomes including obesity, since regular use is common. The question of whether availability and promotion of healthful foods in supermarkets can contribute to reductions in obesity and better health has increasingly become a focus of policy, community nutrition practice, and research in recent years. (Cheadle et al., 1991; Dibb, 2004; Glanz \& Yaroch, 2004; McGinnis, Goodman, \& Kraak, 2006)

There have been conflicting findings on the effects of supermarkets and supercenters on rates of obesity. (Courtemanche \& Carden, 2011; Cummins, Petticrew, Sparks, \& Findlay, 2005; Powell, Han, \& Chaloupka, 2010) This may be due in part to the increased availability of both healthier and less healthy products at lower costs in large stores. A recent review has suggested that in-store marketing interventions that promote healthier choices of items in product categories that consumers may already plan on purchasing could have a positive effect. (Glanz, Bader, \& Iyer, 2012) Healthful food marketing interventions that use a combination of the 4 P's of marketing (product, price, placement, and promotion) may favorably affect purchases of healthier products. (Glanz et al., 2012)

Because supermarkets are commercial enterprises, it is important for the owners, managers, and employees of stores to be a part of marketing interventions within stores. The purpose of this paper is to examine the reaction 
of store employees and customers to a six-month in-store marketing intervention and accompanying evaluation in four large supermarkets in lower income, ethnically diverse neighborhoods in Philadelphia. The intervention focused on increasing purchases of lower calorie options in five product categories: milk, ready-to-eat cereal, frozen meals, in-aisle beverages (primarily soda and water), and checkout cooler beverages (Foster et al., 2014).

\section{Methods}

\subsection{Overview and Intervention Strategies}

The survey data described here were collected as a part of the evaluation of a marketing intervention pilot study in supermarkets. (Foster et al., 2014) The study was conducted at eight stores (four control and four intervention) from two chains, The Fresh Grocer and Brown's Super Stores Inc (ShopRite), in the Philadelphia area. Based on statistics from Policy Map and the US Census, the eight stores met the following eligibility criteria: located in a low- to moderate-income census tract; located in an area of below-average supermarket density; or located in an area having a supermarket customer base with more than 50\% living in a low-income census tract. Stores were paired based on grocery chain, square footage, and the percentage of sales from public health and nutrition programs: WIC (Women, Infants, and Children) and SNAP (the Supplemental Nutrition Assistance Program formerly the Food Stamp Program). The stores in each pair were then randomized into control or intervention groups. The intervention design and product targets is described in great detail in another publication (Foster et al., 2014), but in short, it focused primarily on the placement and promotion of healthier items (defined as lower calories per fixed amount than the top selling item) in the milk, ready-to-eat cereal, in-aisle beverages, checkout cooler beverages, and frozen food sections of the store, as well as secondary placements of these items on endcaps (the end of aisles) and dead space stacks (free standing displays that can be anywhere in the store).

The intervention was intended to be "stealth" and sustainable, and therefore did not use nutrition claims or price reductions/coupons. Instead, the intervention focused on product category management, and consisted of six placement and promotion marketing strategies used across all categories: 1) multiple facings, 2) prime placement, 3) signage, 4) secondary placement, 5) cross promotion, and 6) taste-testing. Each product category employed a different mix of marketing strategies. Intervention strategies in the dairy aisle utilized all six marketing strategies and focused on promoting lower calorie milk products (skim, 1\%, and 2\%), while discouraging purchases of whole milk. To achieve this, the order of the milk displays were changed and the number of facings, the front-of-product packages a consumer can see on the shelf, of whole milk were decreased by $30 \%$, while the facings of the lower calorie milks were increased evenly. Additionally, once a month, samples of the lower calorie milks were available for customers to try. In the other product aisles (cereal, in-aisle beverages, checkout cooler beverages, and frozen food), target products were moved to eye level (strategy \#1), the number of facings were increased (strategy \#2), and call-out signs were placed by the target products (strategy \#3). The call-out signs were produced by each chain and only listed the name and price of the product, but no health information or claims were included. Additionally, milk and cereal were cross promoted (strategy \#5) through dead space stacks of cereal in the diary aisle, and water was cross promoted with diet beverages through dead space stacks of water in the soda aisle.

The intervention was designed, planned and agreed to collaboratively by the research project staff, the grocery chain corporate offices, and the managerial staff in the intervention supermarkets. Store staff implemented the changes with assistance from the research staff. To aid the process, the research staff created "planograms" (Figure 1.) which depicted the desired shelf layout. The in-aisle and front checkout cooler beverage sections of the store are stocked by the beverage companies, so additional conversations with the soda vendors were required. The research staff visited the intervention stores unannounced on a weekly basis to check compliance to the intervention plan and recommend corrections if necessary.

\subsection{Store Manager and Intercept Surveys}

Store manager and customer intercept survey data were collected only in the four intervention stores. The main aims of the store manager surveys were to assess employee reactions to the intervention, the time and effort for implementation, and the feasibility and scalability of continuing the program. The purpose of the customer intercept surveys was to assess whether or not customers noticed the changes in the stores and to better understand the shoppers' reactions in the context of their shopping habits. The study protocol and materials for the store manager surveys were approved by Temple University's Institutional Review Board, and grocers were provided an informational letter. The Institutional Review Board of The University of Pennsylvania approved the study protocol for customer intercept surveys and all participants provided verbal consent and were given a written statement of research. 


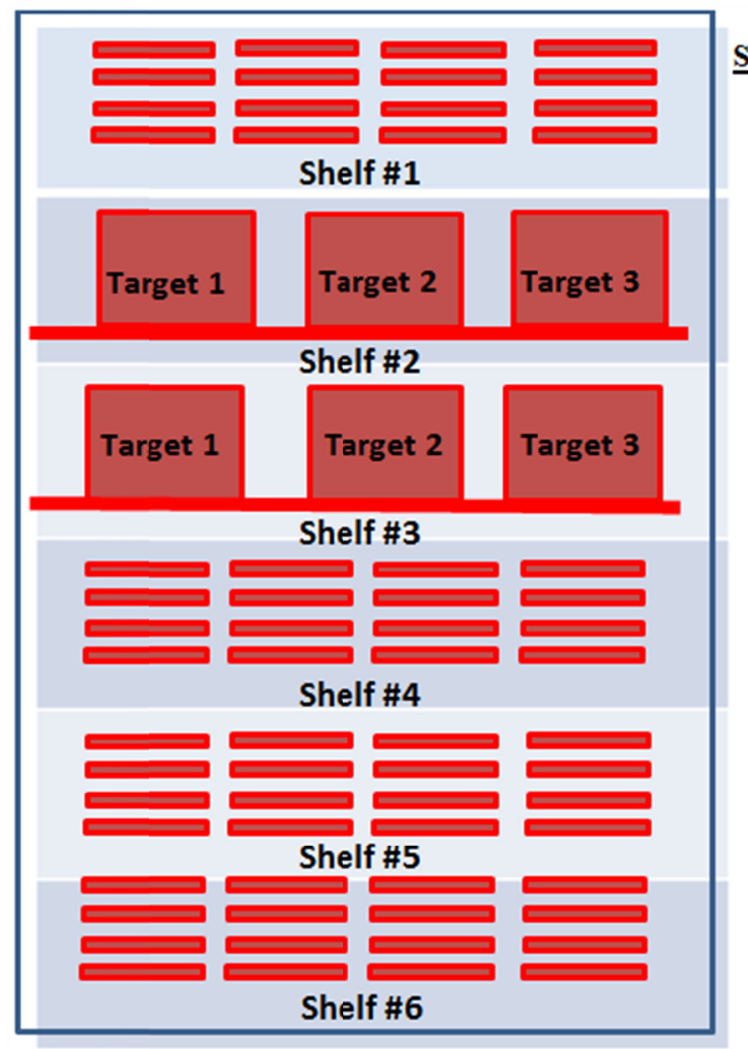

\section{Strategies:}

1. Multiple facings:

a) Give the targeted products 2 facings each

b) Targeted products should be stacked upright (front facing), with the full picture facing out the window

c) All other products should be stocked laying down

2. Prime placement:

a) Place the targeted products on shelves 2 and 3 of refrigerator case, as pictured. Put one facing on each shelf.

b) If possible, nothing should obstruct view of targeted products (e.g., other promotional objects on doors)

3. Call-out signs: Highlight targeted products with call out signs (call out signs will change color each month). Place shelf runners on shelves to highlight products and guide stocking of shelves

4. Taste-testing: N/A

5. Secondary placement: Secondary placements on frozen endcaps should have double the number of targeted products and prime placement (see strategy \#2)

Figure 1. Sample planogram for frozen food aisle in intervention stores

\subsubsection{Store Manager Surveys}

Store manager survey data were collected at the end of the intervention, from May 2012-July 2012. The 13-item survey asked employees to report what grocery chain they worked for, their job title and the primary and secondary intervention product categories (ready-to-eat cereal, frozen food, milk, in-aisle beverages, checkout cooler beverages, overall operations) they worked in. The survey then asked category specific questions, asking employees to rate, on a 7-point scale, how the intervention affected their job. Questions included: whether or not it caused extra work (no extra work to a lot of extra work), had a positive/negative impact on their workloads (extremely negative impact to extremely positive impact), how likely the employees would be to continue or recommend the intervention strategies (not at all likely to extremely likely), and which program components were most helpful (not at all helpful to extremely helpful). The survey also included open-ended response questions related to what the employees liked most and least about the intervention. Study staff personally delivered the surveys to the four intervention stores and asked the managers to distribute the surveys to employees involved in the intervention, which included the overall store operations managers, department managers, and employees involved in changing the layout and maintaining stock of product. After completion, surveys were placed in sealed envelopes by the respondents to ensure anonymity. Surveys were also sent to the corporate offices. Attempts were also made to obtain survey responses from store employees that had been transferred to other stores. No incentives were given to store employees for completing the surveys.

\subsubsection{Customer Intercept Surveys}

Intercept survey data were collected the first week of August 2012 by in-person interviews at the participating stores. Although the surveys were conducted after the completion of the intervention period, all stores were still continuing the intervention at the time of the surveys. To be eligible to complete the survey, the shopper must be between the ages of 18-65 years old, be able to communicate in English, be the primary shopper in their household, and do most of their shopping at the store where the survey was being administered. Shoppers were approached as they were entering or exiting the store and asked if they would like to complete a survey on shopping habits and marketing in the store. If a shopper agreed to complete the survey, they were screened for eligibility, administered verbal consent, and given a written statement of research by trained interviewers. The interviewers then dictated the survey, asking a total of 20 questions which took 10-15 minutes to complete. 
Shoppers were asked questions about their health and demographics, shopping habits, and whether or not they had noticed any changes to the intervention sections of the store. If the shopper reported that they did not notice any changes to the store, the interviewer showed the shopper pictures of the intervention to see if they recognized any changes. Participants received a $\$ 10$ gift card to the grocery chain at which they completed the survey.

\section{Analysis}

Analysis was completed using IBM SPSS 20. Demographic information, shopping habits, and intervention impact were calculated using frequency distributions, cross-tabulation, and analyses of variance. Correlations were calculated using Pearson's R or one-sided Fisher's Exact Test. For the stakeholder surveys, two respondents worked in more than one product category, only their primary category responses were analyzed.

\section{Results}

The four intervention stores are located in West and North Philadelphia in low income, racially diverse neighborhoods.

\subsection{Store Manager Surveys}

A total of sixteen stakeholder surveys were completed, thirteen from employees in the four intervention stores and three surveys were collected from one chain's corporate office. Three of the stores completed three surveys each, and one completed four. All respondents were staff in supervisory roles. Ten respondents were managers who oversaw overall store operations, one was from a human resource coordinator, and four were from category specific managers (two dairy managers, one frozen food manager, and one manager of both cereal and in-aisle beverages).

Overall, the store employees had a positive response to the intervention. The employees reported that implementing and maintaining the intervention components (e.g., maintaining product facings and placement, stocking and ordering products, communication with other category staff) did not create a lot of extra work (mean per component $=1.6-3.8$ on a 7 point scale, $1=$ no extra work, $7=a$ lot of extra work). Further, employees reported that the impact of any additional work the intervention created for parts of their job (e.g., stocking products, staffing, ordering products) was positive (mean $=4.4-5.1$ on a 7 point scale, $1=$ extremely negative impact, $7=$ extremely positive impact). When asked which strategies they were most likely to continue after the intervention, stakeholders responded that they were more likely to maintain the increased number of facings of the healthier products and continue the prime product placement (mean=5.6 and 5.4 respectively on a 7-point scale, $1=$ not at all likely, $7=$ extremely likely). Employees were less likely to express interest in maintaining the secondary placements (mean $=4.2$ ), which were also reported as causing the most additional work.

All program components (e.g. planograms, monthly meetings, weekly store visits) were rated helpful by employees (range 4.6-5.9, median $=4.8,1=$ not at all helpful, $7=$ extremely helpful), with planograms averaging least helpful at 4.6, and weekly visits from project staff most helpful at 5.9.

When asked what they liked the most, four out of ten respondents said the interaction with project staff and the willingness to work to meet the organization's needs. One corporate level employee responded that the project was the "first time that a sustainable program was the ultimate goal." When asked what employees liked the least, two out of five respondents reported that soda vendor cooperation was an issue.

\subsection{Customer Intercept Surveys}

Twenty-five customer intercept interview surveys were completed at each of the 4 intervention stores, for a total of 100 surveys. The age of respondents ranged from 18 to 65 years old, with a mean of 44 years. Of the 100 participants, $89 \%$ self-identified as Black or African American, 39\% reported a household income of less than $\$ 20,000 /$ year, $81 \%$ either completed high school or had some college or technical school education, and 53\% reported having at least one child living in their household. $60 \%$ of the respondents were female. $54 \%$ of participants self-identified their weight status as overweight, $40 \%$ self-identified as the right weight, and $6 \%$ said they were underweight. $34 \%$ of respondents were either WIC or SNAP recipients.

The majority of the shoppers surveyed said they shop at the store at least once a week (75\%) and used the weekly ad or circular to plan their trip at least some of the time (84\%). A large portion of the shoppers used coupons $(71 \%)$, obtaining them from the newspaper $(63 \%)$ or weekly circular $(36 \%)$. Out of the 70 participants who reported use of a shopping list, $69 \%$ said that they usually or always purchase items not on the list.

Of the five intervention product categories (milk, read-to-eat cereal, in-aisle beverages, checkout cooler beverages and frozen food), participants were least likely to say that they would try a new or different type of 
milk (mean $=2.11$, on a scale of $1=$ not likely to $5=$ most likely). The mean likelihood of trying new types of cereal, frozen dinners, and soda ranged from 3.24-3.28 on a scale of 1 (not likely) to 5 (most likely). Women were statistically significantly more likely to report that they would try a new type of soda than men.

Shoppers were more likely to notice any changes in the milk and ready-to-eat cereal aisles ( $28 \%$ and $29 \%$ noted change), and least likely to notice change in the frozen food aisle (16\%). (Table 1) Out of the intervention strategies put in place, layout was most frequently reported as being noticed in all product categories except for the checkout coolers. In the checkout coolers respondents were most likely to notice the proportion of water or diet sodas to regular sodas had changed $(40 \%)$, and participants who do not receive funding from a benefit program were statistically significantly more likely to notice the change $(\mathrm{p}=0.016)$. Females and non-benefit users were more likely to report that the change in checkout coolers affected their purchasing showing significance ( $\mathrm{p}=0.016$ and 0.018 , respectively). There were few significant difference between store chains, although customers were more likely to notice changes in layout in the cereal aisle at one store chain than the other $(47 \%$ versus $14 \%, \mathrm{p}=0.068,0.05$ confidence level $)$.

Table 1. Intervention effect on customers, both store chains combined.

\begin{tabular}{|c|c|c|c|c|c|c|c|c|c|c|}
\hline \multirow{2}{*}{\multicolumn{5}{|c|}{ Did you notice any changes in the following categories? }} & \multicolumn{2}{|c|}{$\begin{array}{l}\text { Yes } \\
(\mathrm{N}=\mathbf{1 0 0})\end{array}$} & & & & \\
\hline & & & & & $\%$ & $N$ & & & & \\
\hline \multicolumn{5}{|l|}{ Milk } & $28 \%$ & 28 & & & & \\
\hline \multicolumn{5}{|l|}{ Cereal } & $29 \%$ & 29 & & & & \\
\hline \multicolumn{5}{|l|}{ Frozen dinners } & $18 \%$ & 18 & & & & \\
\hline \multicolumn{5}{|l|}{ Pepsi } & $23 \%$ & 23 & & & & \\
\hline \multicolumn{5}{|l|}{ Checkout coolers } & $25 \%$ & 25 & & & & \\
\hline \multirow{2}{*}{\multicolumn{5}{|c|}{ If change was noticed, did the change affect purchasing? ${ }^{\mathrm{a}}$}} & \multicolumn{2}{|l|}{ Yes } & & & & \\
\hline & & & & & $\%$ & $N$ & & & & \\
\hline \multicolumn{5}{|l|}{ Milk $(\mathrm{N}=28)$} & $29 \%$ & 8 & & & & \\
\hline \multicolumn{5}{|l|}{ Cereal $(\mathrm{N}=29)$} & $41 \%$ & 12 & & & & \\
\hline \multicolumn{5}{|l|}{ Frozen dinners $(\mathrm{N}=18)$} & $24 \%$ & 4 & & & & \\
\hline \multicolumn{5}{|l|}{ Pepsi $(\mathrm{N}=23)$} & $26 \%$ & 6 & & & & \\
\hline \multicolumn{5}{|l|}{ Checkout coolers $(\mathrm{N}=25)$} & $40 \%$ & 10 & & & & \\
\hline \multirow{2}{*}{$\begin{array}{l}\text { What changes did you notice in } \\
\text { the following product } \\
\text { categories? } \\
\text { (Multiple responses allowed. Both } \\
\text { stores combined) }\end{array}$} & \multicolumn{2}{|c|}{$\begin{array}{c}\text { Milk } \\
(\mathrm{N}=28)\end{array}$} & \multicolumn{2}{|c|}{$\begin{array}{l}\text { Cereal } \\
(\mathrm{N}=29)\end{array}$} & \multicolumn{2}{|c|}{$\begin{array}{l}\text { Frozen } \\
\text { Dinner } \\
(\mathrm{N}=18)\end{array}$} & \multicolumn{2}{|c|}{$\begin{array}{c}\text { Pepsi } \\
(\mathrm{N}=21)\end{array}$} & \multicolumn{2}{|c|}{$\begin{array}{c}\text { Checkout } \\
\text { Coolers } \\
(\mathrm{N}=24)\end{array}$} \\
\hline & $\%$ & $N$ & $\%$ & $N$ & $\%$ & $N$ & $\%$ & $N$ & $\%$ & $N$ \\
\hline Placement of items on shelves & $25 \%$ & 7 & $31 \%$ & 9 & $41 \%$ & 7 & $9 \%$ & 4 & $21 \%$ & 5 \\
\hline Different number of facings & $14 \%$ & 3 & $7 \%$ & 2 & $0 \%$ & 0 & $14 \%$ & 3 & $42 \%$ & 10 \\
\hline Promotions & $14 \%$ & 3 & $14 \%$ & 4 & $12 \%$ & 2 & $5 \%$ & 1 & $17 \%$ & 4 \\
\hline Other $^{b}$ & $54 \%$ & 15 & $62 \%$ & 18 & $53 \%$ & 9 & $71 \%$ & 15 & $42 \%$ & 10 \\
\hline
\end{tabular}

${ }^{a}$ Change in purchasing reflects purchase of a healthier alternative.

b "Other" changes noticed may not have been influenced by the intervention.

\section{Discussion}

Overall, the store employees responded very well to the intervention and the presence of the research team in the stores. One area that proved difficult was when dealing with areas of the stores stocked by outside vendors, specifically in the in-aisle and front checkout cooler beverages, which are the only products included in the study 
that are stocked by outside distributors versus grocery store employees. Although the study team talked to representatives from the soda company while planning the intervention, it would likely be necessary to further involve the distributors for the intervention to be sustainable. Employees particularly enjoyed and encouraged more product sampling and education. Since our pilot intervention focused on sustainable, low cost ways to increase healthy purchasing, increased sampling and education would require more funding as it is not sustainable otherwise.

Store employees valued the interaction from project staff, however, for a larger intervention, additional study staff may not be plausible. A reasonable approach would be to have one employee in each store be responsible for ensuring the changes are complete.

One major limitation of the stakeholder survey was the response rate. Almost all respondents were storewide managers or from the corporate office, so few surveys were received from category or "floor" managers. In addition, despite repeated attempts, the study team only received surveys from one corporate office.

Results from the customer intercept surveys indicated that impulse or unplanned purchases were relatively common, even when using a shopping list. This suggests that in-store or point-of-purchase interventions can be robust opportunities for change. Of customers that noticed changes in the front checkout coolers, $42 \%$ reported noticing an increase of healthier items (water and diet soda), respectively. Data from the intervention study noted that while sales of all checkout cooler sized beverages decreased, sales of water decreased significantly less. (Foster et al., 2014) Based on these observations, interventions focusing on placing healthier products in the checkout aisles of the store may be a good direction to focus.

In addition, the frequency of use of weekly ads to plan shopping trips, and coupon access from weekly ads and newspapers suggest there are opportunities to encourage shoppers to make healthier purchases through print advertising. Since the study stores were in the same region with the same weekly ads, we were not able to control for advertisements, but an intervention in multiple regions could consider this tactic. The intercept surveys also revealed a relatively low rate of noticing the project's interventions, which suggests that perhaps the intervention was too stealth, and more promotion and visibility are needed.

The intercept surveys were a sample of convenience, which may bias response. The surveys were conducted after the completion of the intervention. If the surveys were conducted while the intervention was being monitored by research staff to ensure implementation, the responses may have differed. In addition, there were no baseline surveys conducted, so it is unknown if the changes noted by customers were due to the intervention. Based on the number of customers who responded 'other' to the changes they noticed, it seemed that some of the changes they reported seeing were likely not due to our intervention, but to the introduction of new products or store layout.

\section{References}

Cheadle, A., Psaty, B. M., Curry, S., Wagner, E., Diehr, P., Koepsell, T., \& Kristal, A. (1991). Community-level comparisons between the grocery store environment and individual dietary practices. Preventive Medicine, 20(2), 250-261. http://dx.doi.org/10.1016/0091-7435(91)90024-X

Courtemanche, C., \& Carden, A. (2011). Supersizing supercenters? The impact of Walmart Supercenters on body mass index and obesity. Journal of Urban Economics, 69(2), 165-181. http://dx.doi.org/10.1016/j.jue.2010.09.005

Cummins, S., Petticrew, M., Sparks, L., \& Findlay, A. (2005). Large scale food retail interventions and diet. BMJ (Clinical Research Ed.), 330(7493), 683-684. http://dx.doi.org/10.1136/bmj.330.7493.683

Dibb, S. (2004). Rating retailers for health: how supermarkets can affect your chances of a healthy diet. London: National Consumer Council.

FMI. (2014). US Grocery Shopper Trends: Food Marketing Institute.

FMI. (2015). US Grocery Shopper Trends - Executive Summary: Food Marketing Institute.

Foster, G. D., Karpyn, A., Wojtanowski, A. C., Davis, E., Weiss, S., Brensinger, C., ... Glanz, K. (2014). Placement and promotion strategies to increase sales of healthier products in supermarkets in low-income, ethnically diverse neighborhoods: a randomized controlled trial. Am J Clin Nutr, 99(6), 1359-1368. http://dx.doi.org/10.3945/ajen.113.075572

Glanz, K., Bader, M. D., \& Iyer, S. (2012). Retail grocery store marketing strategies and obesity: an integrative review. Am J Prev Med, 42(5), 503-512. http://dx.doi.org/10.1016/j.amepre.2012.01.013 
Glanz, K., \& Yaroch, A. L. (2004). Strategies for increasing fruit and vegetable intake in grocery stores and communities: policy, pricing, and environmental change. Prev Med, 39(Suppl 2), S75-80. http://dx.doi.org/10.1016/j.ypmed.2004.01.004

McGinnis, M., Goodman, J. A., \& Kraak, V. I. (2006). Food Marketing to Children and Youth: Threat or Opportunity? Washington, D.C.: Institute of Medicine, Food and Nutrition Board.

Powell, L. M., Han, E., \& Chaloupka, F. J. (2010). Economic contextual factors, food consumption, and obesity among U.S. adolescents. J Nutr, 140(6), 1175-1180. http://dx.doi.org/10.3945/jn.109.111526

\section{Copyrights}

Copyright for this article is retained by the author(s), with first publication rights granted to the journal.

This is an open-access article distributed under the terms and conditions of the Creative Commons Attribution license (http://creativecommons.org/licenses/by/3.0/). 